\title{
PAISAGISMO E CERRADO: JARDINS PARA CELEBRAR SAVANAS E CAMPOS BRASILEIROS
}

\author{
LANDSCAPING AND CERRADO: \\ GARDENS TO CELEBRATE BRAZILIAN SAVANNAS AND GRASSLANDS
}

\author{
Mariana de Melo Siqueira \\ Alexandre Sampaio \\ Amalia Robredo \\ Claudomiro de Almeida Cortes \\ João Bernardo de A. Bringel Jr \\ Keiko Fueta Pellizzaro \\ Isabel Belloni Schmidt
}

\section{Resumo}

Este artigo apresenta o projeto Jardins de Cerrado e suas atividades iniciais. Desde 2015, fazemos expedições em busca de plantas (o chamado plant hunting), cultivo de ervas e arbustos nativos, experimentos científicos e jardins experimentais. Testamos metodologias de projeto e implantação, baseadas nos jardins naturalistas contemporâneos. O objetivo do projeto é promover a criação de uma linguagem paisagística que expresse o Cerrado, a savana mais rica em biodiversidade e mais ameaçada do planeta, colocando em evidência as ervas e arbustos que compõem a base de suas formações vegetais. Consideramos que jardins são ferramentas estratégicas para a conservação da biodiversidade, ao contribuir para o aumento da percepção e da valorização da flora nativa pelo público em geral.

Palavras-chave: Arquitetura paisagística. Cerrado. Plantas nativas. Jardins naturalistas. Ecologia urbana. Biodiversidade.

\section{ABSTRACT}

This article presents the Jardins de Cerrado (Cerrado Gardens) project and its initial activities. Since 2015, we make expeditions in search of plants (the so-called plant hunting), cultivation of native herbs and shrubs, scientific and gardening experiments. We test design and implementation methodologies, based on contemporary naturalistic gardens. The project aims at the creation of a landscape design language that expresses the Cerrado, the most biodiverse and threatened savanna on the planet, highlighting the herbs and shrubs that make up the base of its vegetations. We believe that gardens can be strategic tools for the conservation of biodiversity, by contributing to increase the perception and appreciation of native flora by the general public.

Keywords: Landscape architecture. Cerrado. Native plants. Naturalistic gardens. Urban ecology. Biodiversity. 


\section{Brasil, Mais que Florestas e Praias}

"Teus risonhos, lindos campos têm mais flores" (Hino Nacional Brasileiro. Francisco Manuel da Silva, 1831).

Que imagens vêm à mente quando pensamos em paisagens brasileiras?

Se considerarmos os resultados encontrados em buscas na internet, agências de viagens e mesmo livros didáticos, a resposta é: florestas e praias.

A identidade paisagística do Brasil está profundamente ligada aos seus biomas florestais, Amazônia e Mata Atlântica. Mas será que a ideia de 'Brasil, uma nação florestal' faz justiça ao variado conjunto de paisagens deste país de proporções continentais?

Em Conservation in Brazil needs to include non-forest ecosystems, Overbeck et al. (2015) destacam que ecossistemas não-florestais predominam em quatro dos seis biomas reconhecidos no Brasil (Cerrado, Pampa, Caatinga e Pantanal), e cobrem proporções razoáveis dos dois biomas dominados por florestas (Amazônia e Mata Atlântica). Originalmente, áreas naturais abertas somavam cerca de $40 \%$ do território nacional (DURIGAN et al., 2018) e ainda hoje abrigam alta biodiversidade, comparável à das florestas (MYERS et al., 2000).

Os ecossistemas não-florestais podem ser classificados basicamente em campos e savanas. A diferença entre campos, savanas e florestas se expressa na abundância de árvores. Enquanto as florestas se caracterizam pela alta densidade arbórea, com dossel fechado e sombreamento dos estratos inferiores, os campos - no outro extremo - não apresentam árvores. São formações abertas, dominadas por capins e outras ervas (o chamado estrato herbáceo), com ou sem arbustos, adaptados à presença de luz solar direta. As savanas se situam em pontos intermediários nesse gradiente arbóreo: apresentam árvores espalhadas na paisagem, em densidades inferiores às das florestas, compondo comunidades vegetais que também contam com um estrato herbáceo adaptado à luz solar direta (RIBEIRO; WALTER, 2008).
Os serviços ambientais prestados por ecossistemas não-florestais são muito importantes. Além de, globalmente, armazenarem tanto carbono quanto florestas (WHITE et al., 2000), savanas e campos são fundamentais para a manutenção do equilíbrio hídrico, especialmente no que se refere à infiltração de água no solo e consequente abastecimento dos lençóis freáticos (BUSTAMANTE, 2015).

O Cerrado, objeto deste estudo (Figura 1), é um bioma savânico formado por um mosaico de vegetações campestres, savânicas e florestais (RIBEIRO; WALTER, 2008). É a savana mais ameaçada do planeta, tendo ocupado cerca de $22 \%$ do território brasileiro (mais de 2 milhões de $\mathrm{km}^{2}$ ), dos quais hoje restam menos de $20 \%$ sem interferência humana (AGUIAR et al., 2004). Com ocorrência em 11 estados brasileiros, do Paraná ao Piauí e do Mato Grosso à Bahia, o Cerrado tem mais de 12 mil espécies de plantas, das quais mais de $35 \%$ são exclusivas desse bioma (BFG, 2015; KLINK; MACHADO, 2005). Devido ao seu alto endemismo (ocorrência de espécies únicas ao bioma) e às altas taxas de destruição, o Cerrado está entre os hotspots mundiais de biodiversidade (MYERS et al., 2000).

Apesar de muito relevantes do ponto de vista ecológico, os campos e as savanas tendem a ser culturalmente desvalorizados, se comparados às florestas (BOND, 2019). No caso do Cerrado, o desinteresse por essas vegetações fica patente em relatos de pessoas que contribuíram ativamente para a formação do imaginário nacional. Os diários de viajantes naturalistas do século 19, por exemplo, revelam a busca de um exótico idealizado raramente encontrado em longas travessias pelo Cerrado, permeadas por momentos de melancolia e tédio.

As formações abertas, que apresentam poucas árvores, pequenas, de troncos retorcidos e folhas coriáceas, dificilmente se enquadram na descrição de uma bela paisagem para nossos autores. [...] As formações mais altas e densas, principalmente aquelas que, devido à umidade dos cursos d'água tornam-se mais altas e exuberantes, típicas das matas de galeria e matas ciliares, são preferidas pelos 


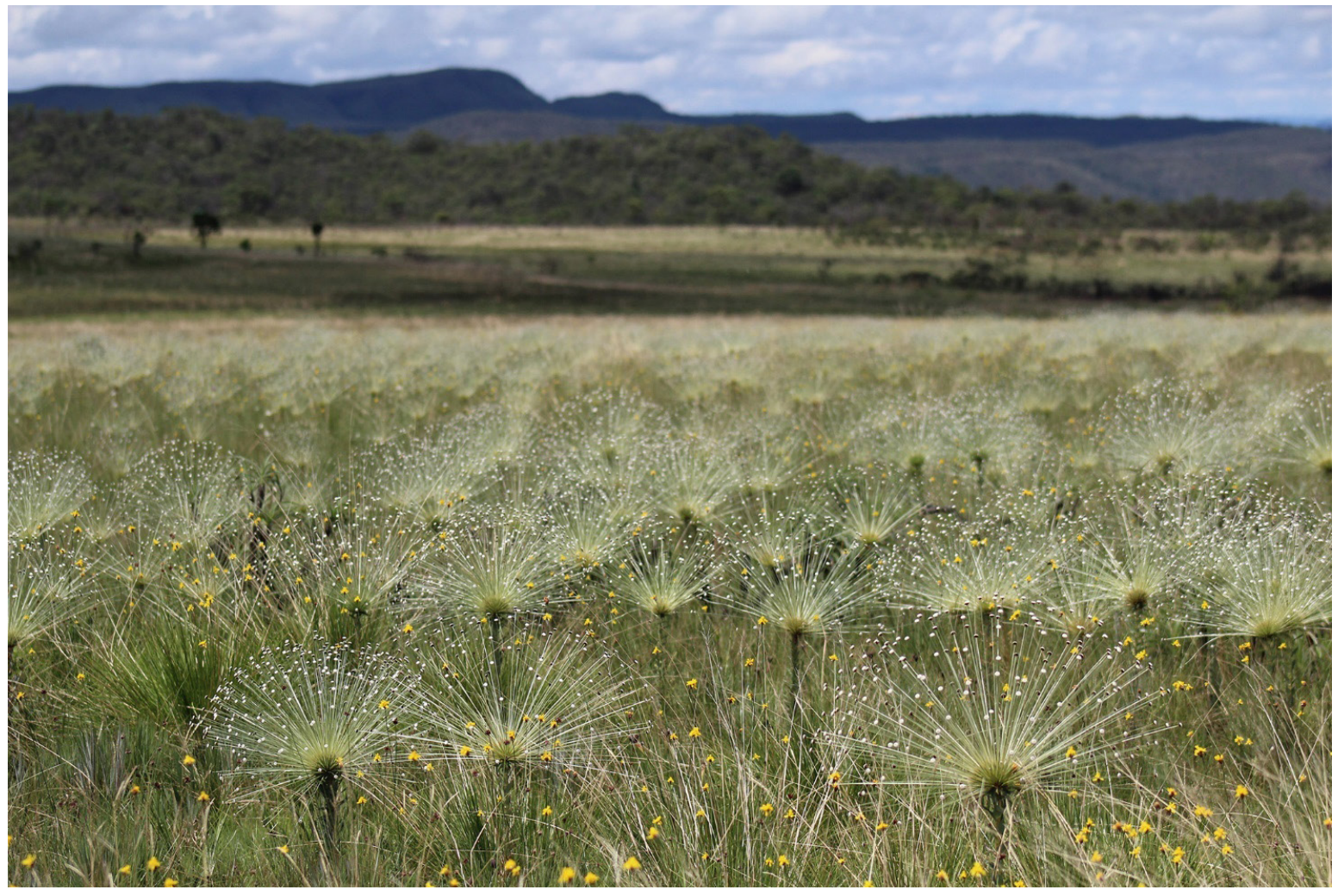

Figura 1 - Fitofisionomias do Cerrado no Parque Nacional da Chapada dos Veadeiros-GO. Em primeiro plano, uma formação campestre, com predominância de gramíneas, semprevivas (Eriocaulaceae) e outras ervas. No morro ao fundo, uma formação florestal, com alta densidade arbórea. Entre eles, formações savânicas, caracterizadas pela presença de árvores espalhadas sobre um estrato herbáceo-arbustivo. Foto: Mariana Siqueira, 2018.

viajantes em comparação às formações abertas e áridas (PASTORE, 2014, p. 150).

A mesma visão é expressa, mais de um século depois, pelo presidente Juscelino Kubitschek, responsável pela construção de Brasília, erigida no coração do Cerrado:

O cerrado, cobrindo a terra vermelha, só interrompida pelos cursos d'água, que corriam em diferentes direções. Aqui e ali surgiam tufos densos de árvores maiores, principalmente nas proximidades dos cursos d'água, e cuja cor, de um verde mais escuro, contrastava, de forma chocante, com a homogeneidade do cinzento sujo do cerrado (KUBITSCHEK, 2006).

Ecólogos consideram que "além de não serem valorizados, os ecossistemas não-florestais são geralmente mal compreendidos em sua forma e funcionamento" (DURIGAN et al., 2018, p. 13), o que pode levar a consequências dramáticas. Políticas públicas permitem - e mesmo incentivam - a destruição desses ambientes como se não houvesse consequências sociais, climáticas e ambientais, resultando em taxas de desmatamento do Cerrado cinco vezes maiores que da Amazônia entre 2013 e 2015 (IPAM, 2017). Chamam a atenção as peculiaridades de algumas das fortes ameaças à biodiversidade dos ecossistemas não-florestais como podem ser, atualmente, o plantio indiscriminado de árvores (por vezes feito no intuito de sequestrar carbono e mitigar os efeitos das mudanças climáticas) e a supressão de distúrbios importantes como o fogo (VELDMAN, 2015b).

Fica clara, assim, a necessidade de ampliarmos nossa compreensão sobre esses tipos de ambientes. A Ciência mostra o caminho e a legislação deve acompanhá-la, "but first the importance of non-for- 
est ecosystems to biodiversity conservation and ecosystem services in Brazil must be recognized by the public" (Overbeck et al., 2015, p. 1458).

\section{Cerrado, (muito) mais que árvores}

As plantas do estrato herbáceo-arbustivo dos ecossistemas nãoflorestais constituem a base de suas vegetações e respondem por enorme parcela de sua biodiversidade, além de prestarem serviços ecossistêmicos importantíssimos. Mesmo assim, há uma desbalanceada valorização das árvores em detrimento das 'plantas baixinhas', denunciada pelos cientistas de forma crescente neste século 21 (BOND, 2019) como no emblemático artigo "Tyranny of trees in grassy biomes", publicado na revista Science (VELDMAN, 2015a). No Cerrado, por exemplo, para cada espécie de árvore, existem pelo menos seis espécies de arbustos, subarbustos, ervas e lianas (MENDONÇA et al., 2008).

Iniciativas científicas, técnicas e artísticas têm buscado superar tal desequilíbrio. Nesse sentido, leis, experimentos e práticas de restauração ecológica têm aceito, incentivado e desenvolvido técnicas para semeadura e plantio, em larga escala, de espécies não-arbóreas no Cerrado (CHAVES et al., 2015; SAMPAIO et al., 2015). Por exemplo, entre 2012 e 2019, foram semeados mais de 200 hectares de áreas a restaurar usando espécies de capins, ervas, subarbustos, arbustos e árvores especialmente no Distrito Federal e em Goiás (PELLIZZARO et al., 2017; SOUSA; VIEIRA, 2017; Figura 2), indicando que surgem resultados efetivos de valorização dessas importantes formas de vida vegetais.

Esse movimento também ocorre no mundo das artes, em iniciativas como o projeto Cerrado Infinito, um plantio de vegetação nativa do Cerrado paulistano desenvolvido pelo artista plástico Daniel Caballero e seus colaboradores em São Paulo. O projeto é complementado por ilustrações (Figura 3) que colocam em foco plantas de um Cerrado que está desaparecendo dos mapas geográficos antes que possa figurar dignamente em nossos mapas mentais e culturais.
Em resumo, o Brasil abriga a savana mais rica em biodiversidade do planeta, cuja riqueza florística está, sobretudo, nos capins, ervas e arbustos que compõem suas paisagens abertas e ensolaradas. Urge fomentar o interesse da sociedade pelo Cerrado e por suas plantas, de forma a contribuir para a conservação de sua biodiversidade e a perpetuação dos serviços ecossistêmicos relacionados.

\section{Projeto Jardins de Cerrado}

Por que o Cerrado não recebe tanta atenção? [...] As respostas não são completamente fáceis ou únicas, mas o olhar e a sensibilização - pelo menos a que cabe aos brasileiros - precisa de urgente mudança em seu foco (Bruno Walter. In: DURIGAN et al., 2018, p. 11).

Como a arquitetura paisagística pode contribuir para o reconhecimento e a valorização dos ecossistemas não-florestais brasileiros? Acreditamos que esse caminho deve, necessariamente, colocar em evidência as plantas do estrato herbáceo-arbustivo que caracterizam seus campos e savanas.

Roberto Burle Marx e um coletivo de botânicos, paisagistas e outros profissionais trabalharam juntos no sentido de introduzir espécies nativas do Brasil ao paisagismo, contribuindo para a superação de uma visão depreciativa da matéria vegetal nacional (DOURADO, 2009). Graças a esse trabalho e ao daqueles que nele se inspiraram, hoje há grande valorização, no paisagismo brasileiro, dos chamados jardins tropicais, elaborados a partir de um rol significativo de plantas nativas - sobretudo de formações florestais e de afloramentos rochosos - que se tornaram comercialmente disponíveis em viveiros.

Já as ervas e os arbustos próprios de formações abertas de savanas e campos brasileiros têm sua utilização em paisagismo historicamente pouco experimentada e difundida. Essa tendência começa a se alterar nos últimos anos (MELLO; PASTORE, 2020). Neste artigo listamos experiências desenvolvidas pelo projeto Jardins de Cerrado desde sua criação em 2015, inspiradas pela obra de Burle Marx e 


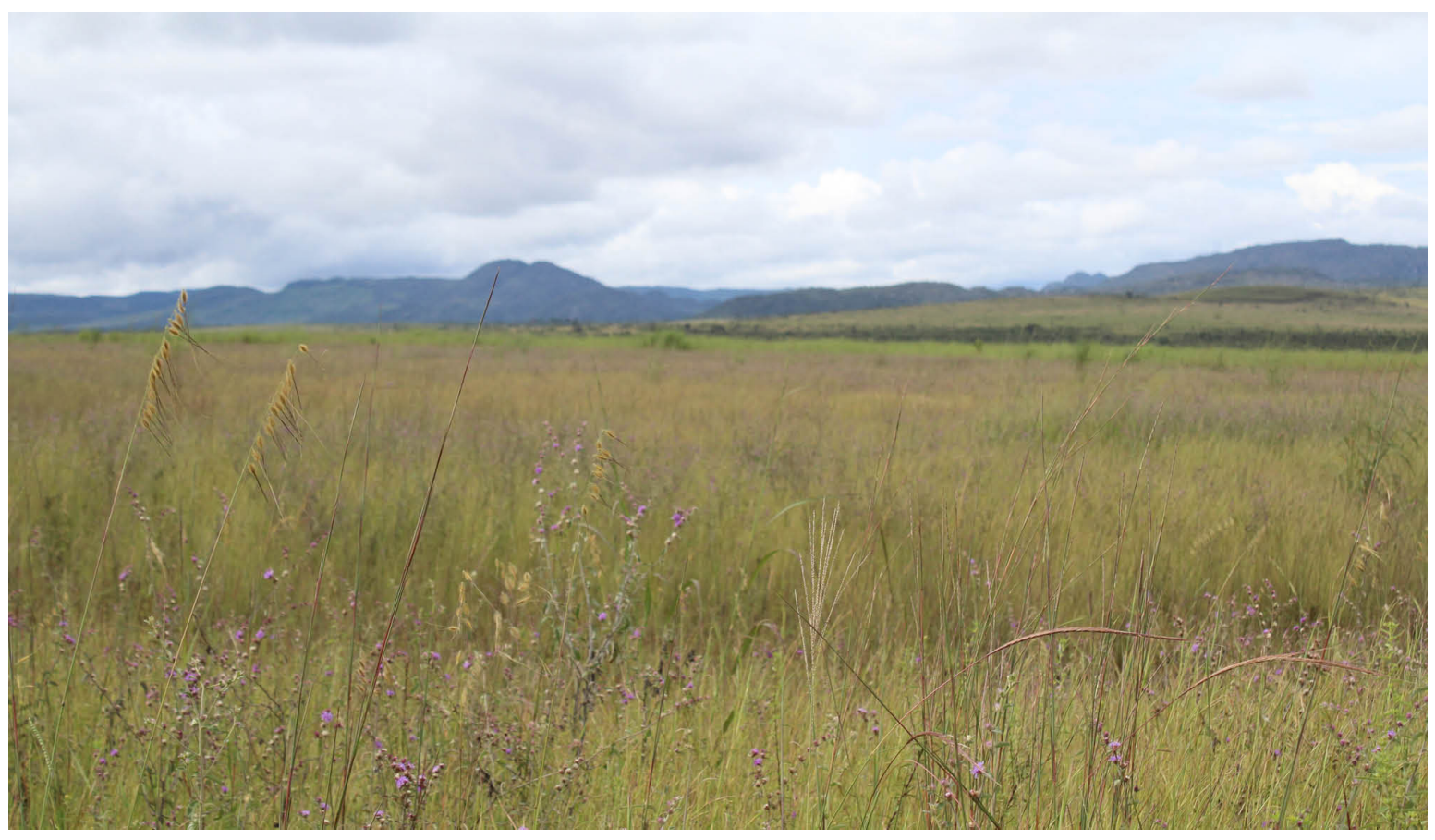

Figura 2 - Área em processo de restauração ecológica por semeadura direta no Parque Nacional da Chapada dos Veadeiros, GO, a partir de uma

variada paleta de capins, ervas, arbustos e árvores. A imagem registra a área um ano e meio após a semeadura. Foto: Mariana

Siqueira, 2018.

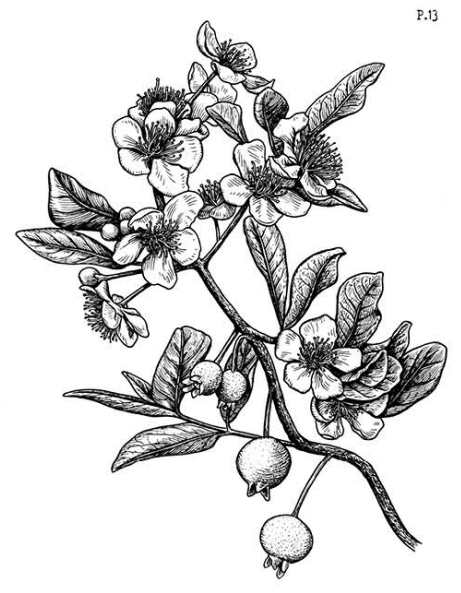

CAMPOMANBSIA pubescens

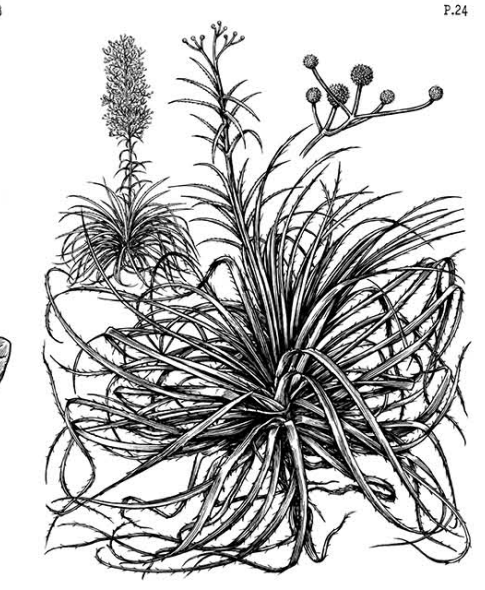

BRYMGIUM horricium

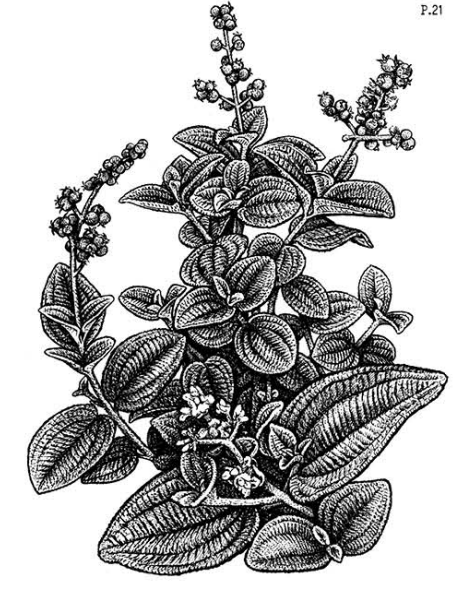

LEANDRA erostrat

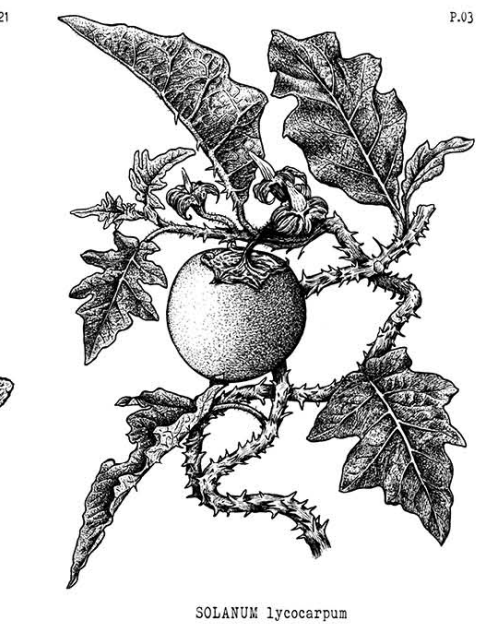

SOLANUM 1ycocarpan

Figura 3 - Ilustrações do livro Guia de Campo dos campos de Piratininga, ou O que sobrou do cerrado paulistano ou Como fazer seu próprio Cerrado Infinito, de Daniel Caballero (2016). 
pelos jardins naturalistas contemporâneos ${ }^{1}$. O objetivo do projeto é contribuir para a criação de uma linguagem paisagística que expresse savanas e campos do Cerrado e valorize a conservação de sua biodiversidade. Para isso, desenvolve atividades projetuais, científicas e pedagógicas, como expedições, introdução de plantas nativas ao paisagismo e experimento científicos e de jardinagem, além de cursos e palestras.

\subsection{Expedições em Busca de Plantas (Plant Hunting)}

Quero dizer-lhes algo sobre a atração violenta que sinto pelas viagens em busca de novas plantas. É como se a floresta estivesse a oferecer um tesouro, que existe apenas para aquele que o busca. Cada dia que passa, mais sinto o quanto é breve a minha vida para conhecer e explorar todos os tesouros da flora brasileira (Roberto Burle Marx. In: TABACOW, 2004, p. 18).

Fazemos expedições em busca de plantas com potencial paisagístico em formações savânicas e campestres do Cerrado, sobretudo na região da Chapada dos Veadeiros, Goiás, e no Distrito Federal (Figura 4). As saídas a campo ocorrem em variadas épocas do ano, para levantamento de dados sobre a fenologia e o aspecto das plantas em todas as estações. Um dos desafios mais interessantes é encontrar plantas que se mostrem atrativas mesmo na estação seca, quando chamam a atenção os dourados e outros tons metálicos assumidos especialmente pelas gramíneas, a inesperada presença de flores e a surpreendente beleza de frutos e sementes.

Uma vez selecionada em campo, a espécie pode ser fotografada, georreferenciada e medida em altura e diâmetro. São levantadas as características ambientais das áreas onde ocorrem, além de aspectos gerais das comunidades vegetais às quais pertencem e sua disposição espacial em relação às outras plantas. Se permitido na

1 O naturalismo é uma vertente do paisagismo contemporâneo caracterizada por jardins inspirados em comunidades vegetais naturais, tanto em termos estéticos - ao manifestarem uma aparente desordem que nos leva ao paradoxo de "projetar a espontaneidade" - quanto em termos ecológicos, por incorporarem conceitos como alta diversidade e alta densidade de plantio (OUDOLF; KINGSBURY, 2013). área, são coletados ramos para herborização e identificação botânica. Em três anos, o projeto Jardins de Cerrado foi responsável pela coleta de amostras de mais de 300 espécies com potencial paisagístico, depositadas no Herbário da Universidade de Brasília (UB).

\subsection{Cultivo de Ervas e Arbustos Nativos do Cerrado}

Para que plantas nativas com potencial paisagístico de fato cheguem ao mercado, é essencial desenvolver formas de cultivo e demonstrar a viabilidade de sua utilização sem jardins. Em março de 2017, foi construído um viveiro experimental na Vila de São Jorge, em Alto Paraíso de Goiás-GO, com o objetivo de testar o cultivo de ervas (inclusive gramíneas), arbustos e subarbustos típicos das formações campestres e savânicas do Cerrado (Figura 5). No viveiro já foram reproduzidas, sempre por semeadura, mais de 55 espécies nativas (Tabela 2), parte já introduzida com sucesso em jardins experimentais.

\subsection{Experimentos Científicos}

\section{Experimento no Jardim Botânico de Brasília (Janeiro, 2016)}

Em janeiro de 2016, estabelecemos no Jardim Botânico de Brasília um experimento de $450 \mathrm{~m}^{2}$, dividido em 180 parcelas de $1 \times 1 \mathrm{~m}$, em que foram semeadas 15 espécies com potencial ornamental (BOKOS, 2017; Figura 6A).

Metade das parcelas experimentais foi irrigada durante a primeira estação seca (maio-outubro de 2016), resultando em diferenças visuais relativamente pequenas em comparação àquelas que não foram irrigadas (Figuras 6B a 6D). A irrigação implicou de forma heterogênea no incremento do crescimento da parte aérea de algumas espécies (COUTINHO et al., dados não publicados). As plantas utilizadas atraíram polinizadores nativos, incluindo espécies raras de abelhas (CAMILO et al., 2018).

Ao início da terceira estação chuvosa, em novembro de 2017, metade do experimento recebeu poda drástica (50\% da área irrigada 

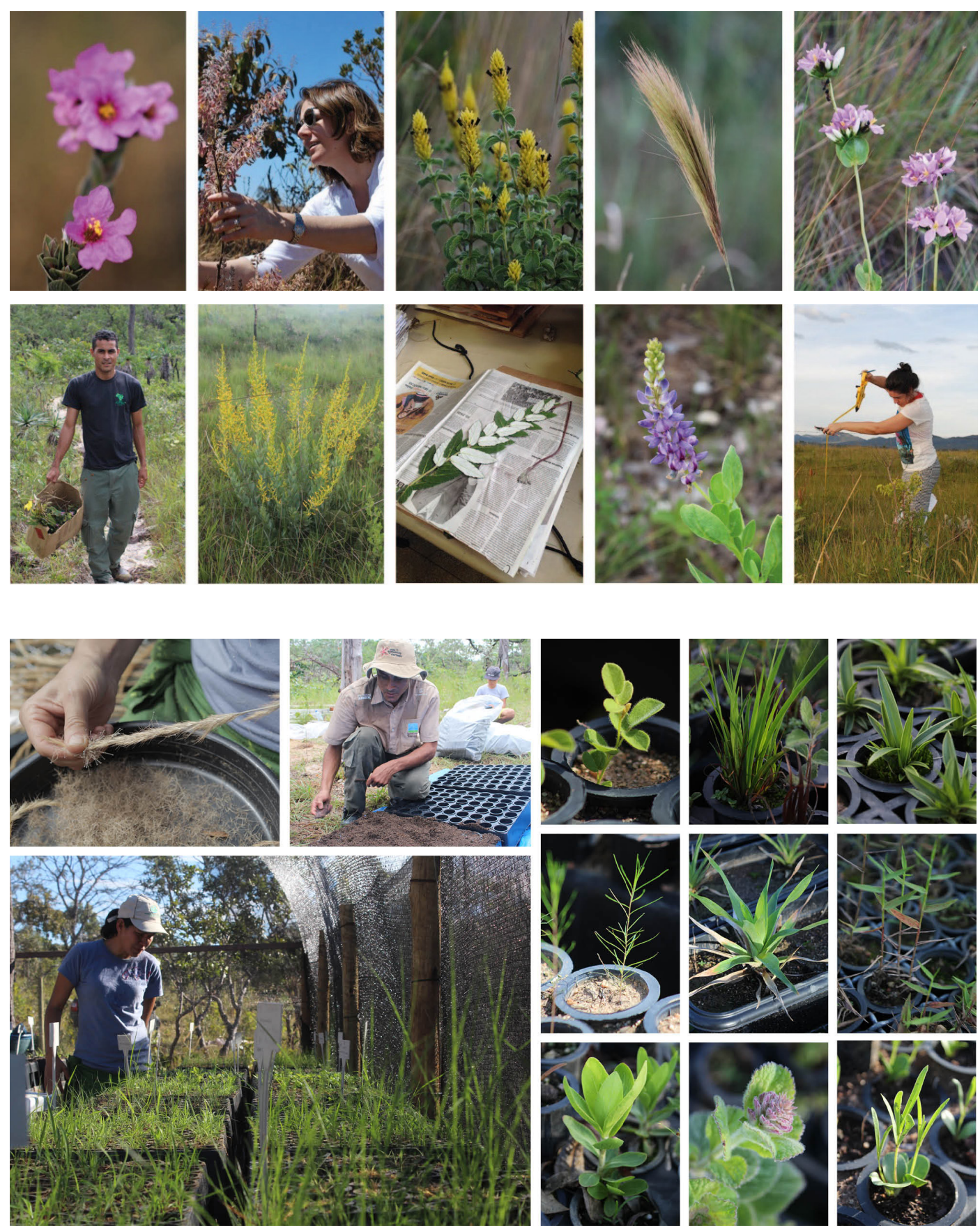

Figura 4 - Desde 2015, são feitas

saídas a campo para prospecção

de espécies nativas com potencial

paisagístico. A maioria das expedições

acontece na Chapada dos Veadeiros,

GO. Fotos: Amalia Robredo e Mariana

Siqueira, 2016 e 2017

Figura 5 - Viveiro experimental

construído em parceria com o projeto

Jardins de Cerrado. Fotos: Mariana

Siqueira, 2017 e 2018; exceto foto

superior à esquerda, de Dani Azul, 2017. 

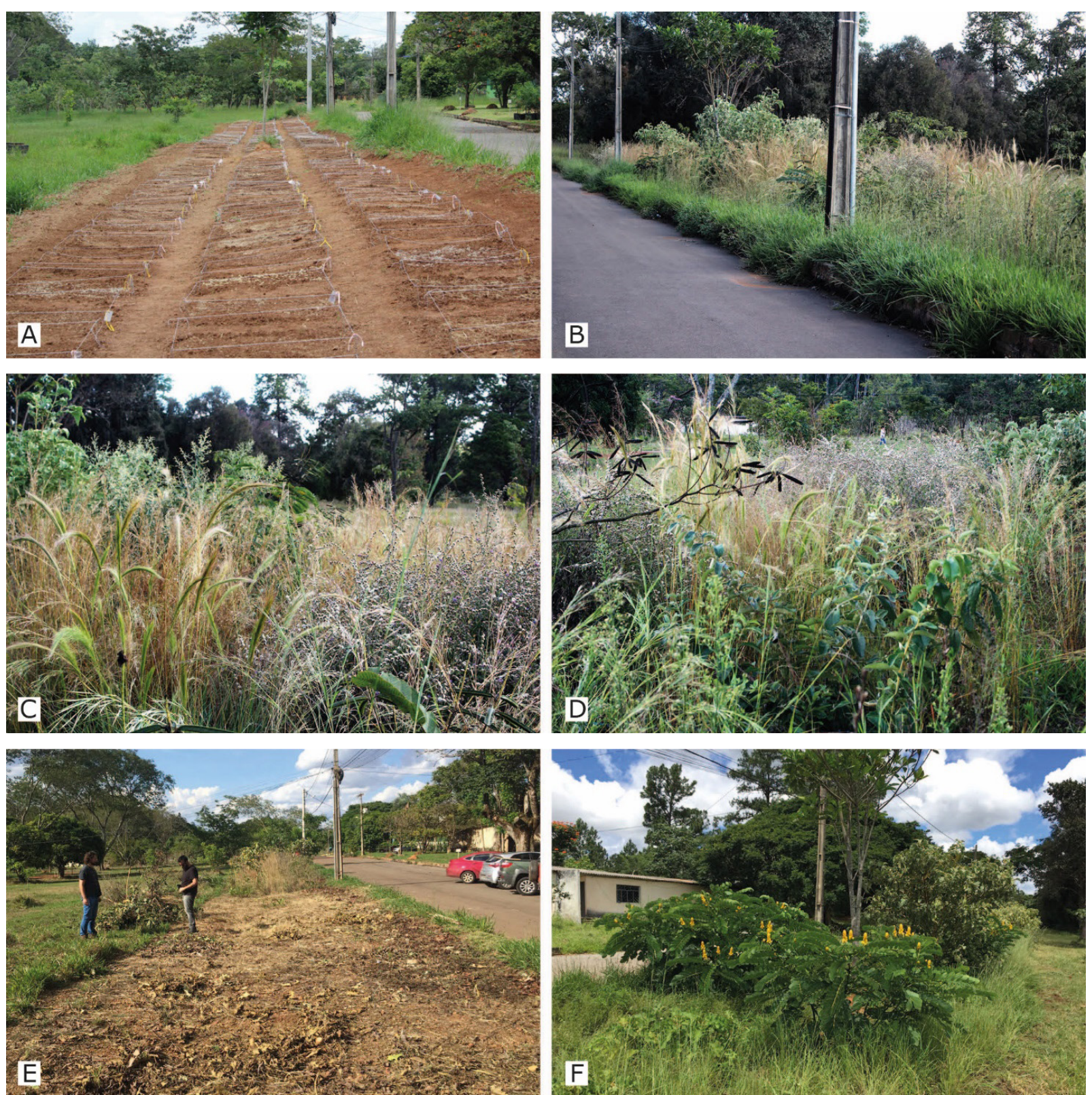

Figura 6 - A. Semeadura em

30/01/2016; B-D. Experimento em 26/05/2017, após duas estações

chuvosas, com grande similaridade

entre a parte irrigada e a não

irrigada; E- Poda drástica efetuada em metade das parcelas em 13/11/2017; F- Area que recebeu poda drástica, quatro meses e meio depois, em 25/03/2018, com sucesso na rebrota da maioria das espécies. Fotos: Mariana Siqueira, 2016-2018.

Mariana de Melo Siqueira, Alexandre Sampaio, Amalia Robredo Claudomiro de Almeida Cortes, João Bernardo de A. Bringel Jr, Keiko Fueta Pellizzaro, e Isabel Belloni Schmidt 
e $50 \%$ da área não irrigada; Figura $6 \mathrm{E}$ ). O objetivo foi observar a resposta da vegetação àquela que é considerada uma forma de manejo crucial nos jardins naturalistas contemporâneos em países de climas temperados (OUDOLF; KINGSBURY, 2013), usada para renovar a parte aérea das plantas ao remover estruturas secas e/ou mortas e possibilitar a rebrota de novas estruturas. A poda drástica tem, sobretudo, uma função estética, mas responde também a questões de segurança, dado que a palhada seca de um jardim dominado por gramíneas, mantido com pouca ou nenhuma irrigação, poderia facilitar a ocorrência de incêndios.

Ainda que o uso de plantas herbáceas do Cerrado no paisagismo seja novidade, a capacidade de rebrota dessas plantas é uma característica evolutiva, selecionada por eventos de fogo natural (SIMON et al., 2009). Isso porque o fogo pode ser descrito como um herbívoro generalista, que consome a parte aérea de plantas além de reduzir a cobertura do solo, acelerar a ciclagem de nutrientes e estimular a rebrota a partir de reservas subterrâneas de energia (BOND; KEELEY, 2005). Dessa forma, a hipótese de que estas espécies rebrotariam após poda drástica foi levantada, e confirmada para a maior parte das espécies. Em poucos meses, todas as gramíneas recuperaram sua parte aérea e duas arvoretas (Senna alata e Solanum lycocarpum) alcançaram a altura daquelas que não foram cortadas (COELHO, 2019; Figura 8F).

\section{Experimento no Instituto de Ciências Biológicas da UNB (DEZEMBro, 2017)}

Um passo importante e emblemático para o uso de herbáceas nativas do Cerrado no paisagismo foi o estabelecimento do experimento Manejo de ervas e subarbustos do Cerrado para uso paisagístico, em dezembro de 2017, dentro da área do Instituto de Ciências Biológicas da Universidade de Brasília (UnB). Coordenado pelo professor de paisagismo da Faculdade de Agronomia e Veterinária da mesma instituição, Júlio Barêa Pastore, em parceria com a prefeitura do campus, o Departamento de Ecologia e o projeto Jardins de Cerrado, o experimento foi organizado em 75 parcelas de $1 \times 1 \mathrm{~m}$ onde foram testadas 10 espécies com diferentes formas de introdução (mudas e sementes) e tratamentos de solo (GRANZOT-
TO, 2018). Esse experimento ocorreu paralelamente ao estabelecimento do primeiro Jardim de Cerrado de Brasília, o Jardim Louise Ribeiro, dentro do mesmo instituto, e deu suporte à expansão do uso de plantas herbáceas nativas no paisagismo de toda a UnB, coordenada por esse professor.

\subsection{JARDINS EXPERIMENTAIS}

Entre 2016 e 2019, fizemos oito jardins experimentais (Tabela 1) utilizando exclusivamente capins, ervas e arbustos nativos do Cerrado. Nossa premissa é que, além de fortalecer identidades locais, as plantas autóctones tendem a ser mais adaptadas às condições climáticas e edáficas, podendo diminuir investimentos em irrigação, alteração de solos e manutenção em geral (OUDOLF; KINGSBURY, 2013).

Tabela 1 Jardins experimentais com ervas e subarbustos nativos do Cerrado executados no âmbito do projeto Jardins de Cerrado entre 2016 e 2019.

\begin{tabular}{l|c|c|c|c}
\cline { 2 - 5 } & $\begin{array}{c}\text { Semeadura } \\
\text { direta }\end{array}$ & $\begin{array}{c}\text { Plantio } \\
\text { de mudas }\end{array}$ & $\begin{array}{c}\text { Espaços } \\
\text { públicos* }\end{array}$ & $\begin{array}{c}\text { Jardins } \\
\text { privados }\end{array}$ \\
\hline $\begin{array}{l}\text { Parque Nacional de } \\
\text { Brasília, 2016 }\end{array}$ & $\bullet$ & & $\bullet$ & \\
\hline Casa no Cerrado, 2017 & $\bullet$ & & & $\bullet$ \\
\hline $\begin{array}{l}\text { Jardim Louise Ribeiro, } \\
2017\end{array}$ & $\bullet$ & & $\bullet$ & \\
\hline $\begin{array}{l}\text { Parque da Asa Sul, } \\
2017\end{array}$ & $\bullet$ & & $\bullet$ & \\
\hline Seagri, 2017 & $\bullet$ & & $\bullet$ & \\
\hline $\begin{array}{l}\text { Floresta Nacional de } \\
\text { Brasília (Flona), 2018 }\end{array}$ & $\bullet$ & & & \\
\hline Casa Vila Rica, 2019 & $\bullet$ & & & \\
\hline Casa Jubarte, 2019 & $\bullet$ & & & \\
\hline
\end{tabular}

* Processos colaborativos e abertos à comunidade.

Fonte: autores. 
Em termos de linguagem, temos como ponto de partida o paisagismo naturalista contemporâneo, por meio do estudo da obra de profissionais como Piet Oudolf, James Hitchmough e Nigel Dunnett. As vegetações de climas temperados que inspiram seus trabalhos, como prados e estepes, guardam semelhanças ecológicas com savanas e campos do cerrado. Entre os pontos em comum, destacamos: camada contínua de estrato herbáceo-graminoso e marcada sazonalidade, com consequentes variações na fenologia das plantas como perda de folhas, dormência de estruturas vegetativas, morte de partes aéreas e posterior rebrota nos períodos favoráveis (SIQUEIRA et al., 2017). Tendo em vista semelhanças ecológicas e visuais entre essas vegetações, apostamos no naturalismo contemporâneo como fonte de metodologia para o desenvolvimento de uma linguagem que permita representar savanas e campos do Cerrado através de jardins.

A sazonalidade é, não apenas expressa, mas celebrada pelos jardins naturalistas contemporâneos (Figura 7). Consideramos que a valorização dessa que é uma característica central na ecologia e no cromatismo das paisagens do Cerrado (Figura 7 e 8) seja crucial para a ampliação da percepção e da valorização da savana brasileira pelo público em geral.
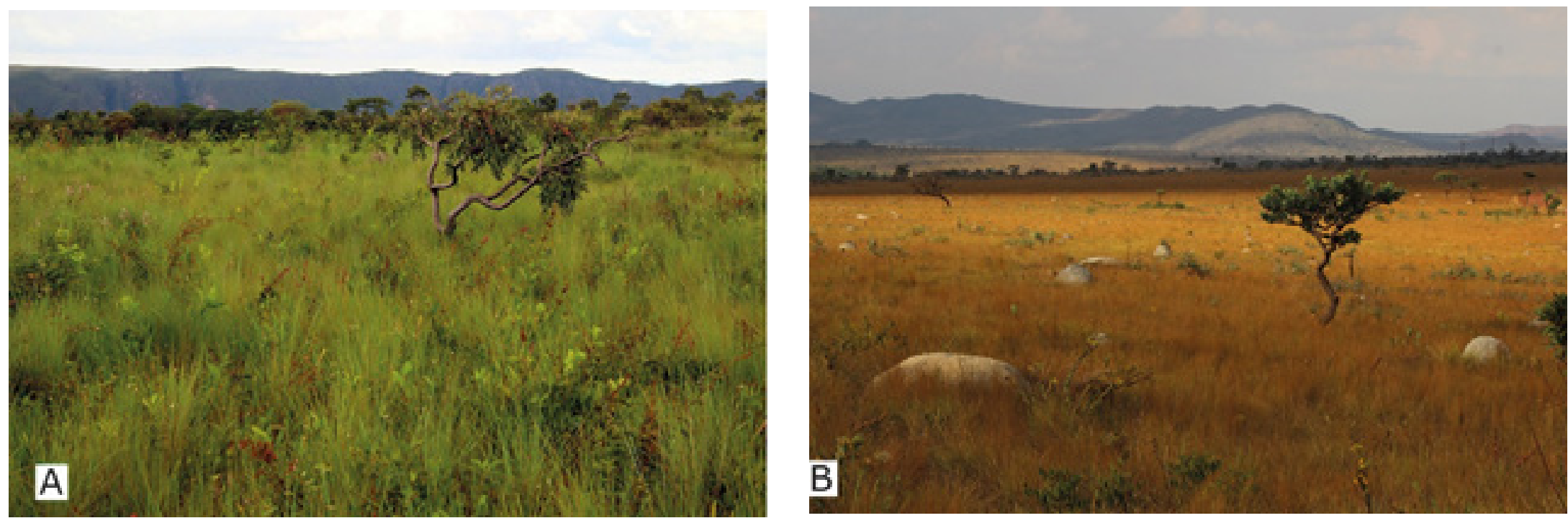

Figura 7 - O contraste entre as estações de chuva e de seca na Chapada dos Veadeiros em fevereiro (A) e agosto (B), respectivamente. Fotos: Mariana Siqueira, 2016. 

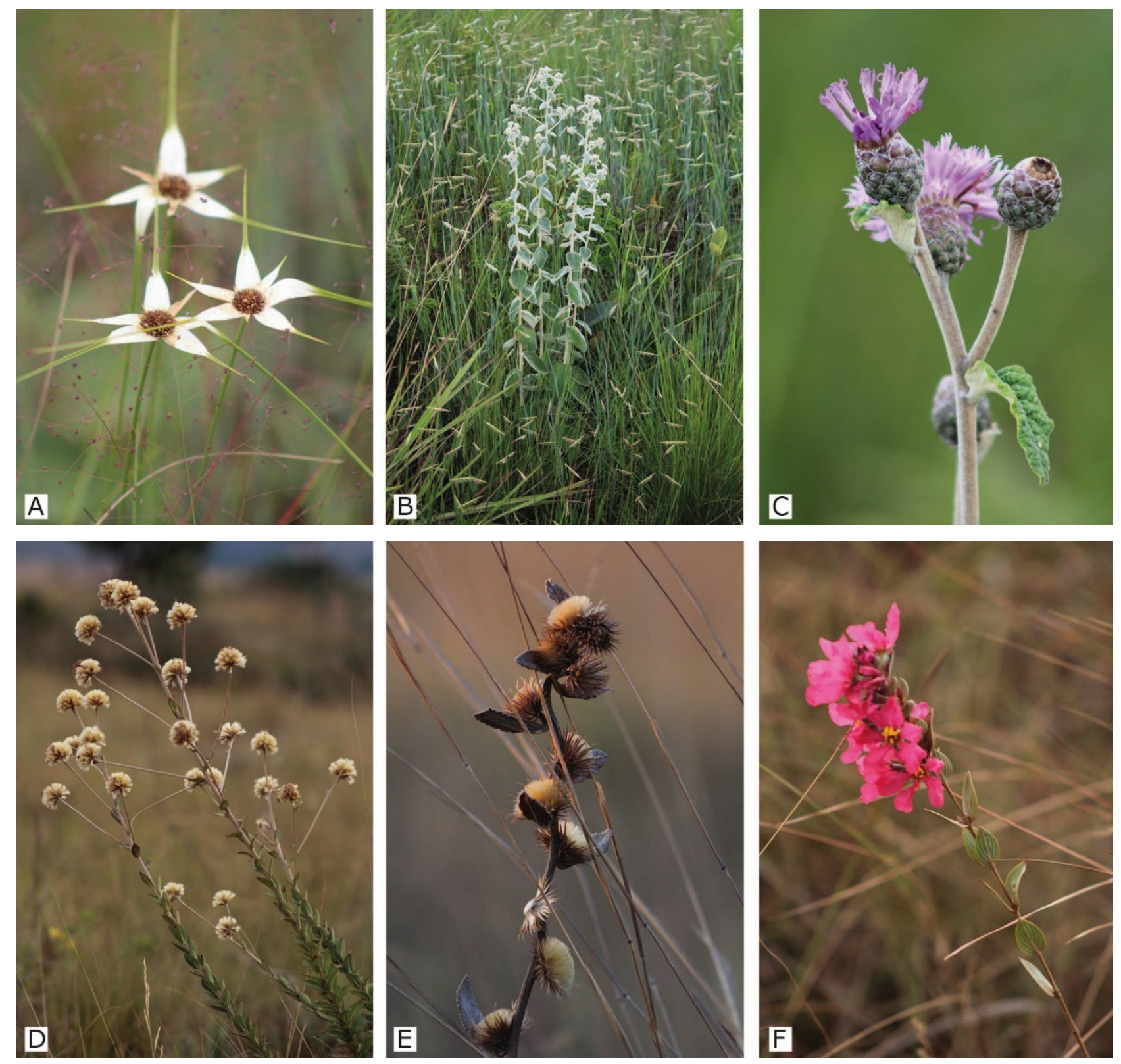

Figura 8 - Plantas do Cerrado durante a estação chuvosa

(outubro a março; $\mathrm{A}-\mathrm{C}$ ) e a

estação seca (abril a setembro:

D-F).

Fotos: Mariana Siqueira, 2016 a 2018.

F 


\section{Casa no Cerrado (novembro, 2017)}

A 'Casa no Cerrado', projeto e propriedade do arquiteto Carlos Teixeira, do escritório Vazio SA., foi construída em um condomínio com vegetação savânica excepcionalmente bem conservada na Serra da Moeda, em Moeda-MG.

Uma vez finalizada a obra, taludes foram estabilizados por meio da semeadura de capim-braquiária (Urochloa sp.), espécie africana introduzida no país para a formação de pastagens. O capim, que apresenta amplas vantagens competitivas em relação a plantas nativas (PIVELLO et al., 1999), aumentou sua área de ocorrência na Casa no Cerrado ano após ano, ameaçando tanto o equilíbrio eco- lógico das áreas nativas adjacentes quanto a integração cromática e estética entre a construção e seu contexto paisagístico.

A primeira área a receber a substituição das gramíneas exóticas por plantas nativas em um jardim de Cerrado foi o talude mais diretamente ligado à casa, com cerca de $60 \mathrm{~m}^{2}$, onde, no dia 19/11/2017, foram semeadas 22 espécies de capins, ervas e subarbustos nativos do Cerrado (Tabela 2).

Um ano depois, cerca de $75 \%$ do jardim estava coberto por 16 espécies nativas, época em que as áreas ainda livres foram ressemeadas com novas espécies. Com o passar do tempo, tornou-se evidente a expressão da sazonalidade no jardim (Figura 9).
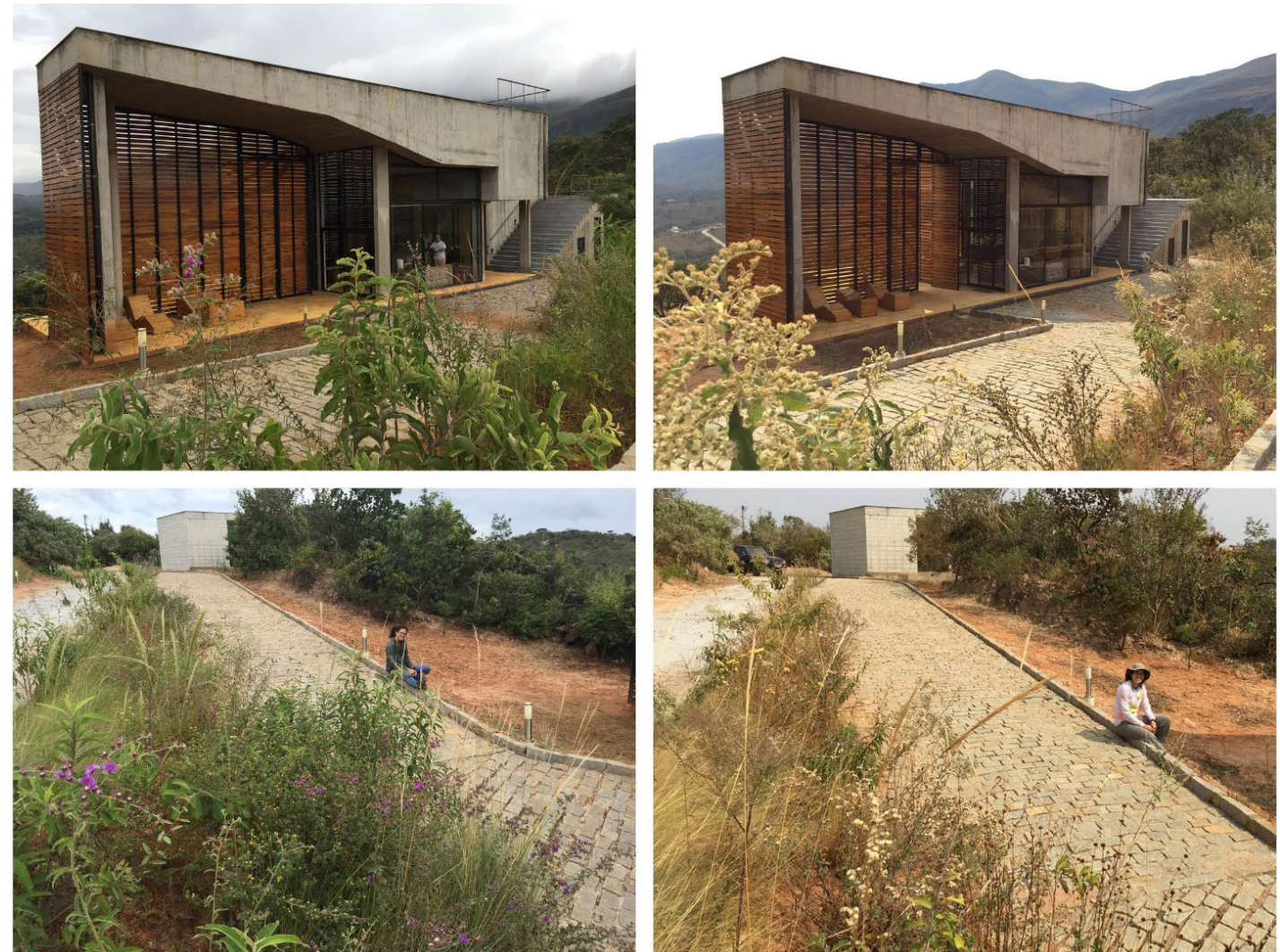

Figura 9 - Do lado esquerdo, imagens do jardim com 17 meses, durante a segunda estação chuvosa. Do lado direito, jardim com 21 meses, durante a estação seca seguinte. Fotos: Mariana Siqueira, 2019 


\section{Jardim Louise Ribeiro (Dezembro, 2017)}

Em 10 de março de 2016, o Instituto de Ciências Biológicas da UnB foi palco de uma das maiores tragédias de sua história, o feminicídio da aluna Louise Maria Ribeiro pelo ex-namorado. Após o plantio de uma muda de ipê para simbolizar a presença da aluna, a comunidade acadêmica se organizou para projetar e plantar um extenso jardim que pudesse não só manter viva a memória de Louise, mas também representar o desejo por uma sociedade mais justa para as mulheres. O Cerrado foi escolhido como símbolo de resistência e transformação e, nesse contexto, o projeto Jardins de Cerrado foi convidado a somar-se ao coletivo de alunos e professores, entre outros, que idealizavam a intervenção.

Entre maio de 2016 e dezembro de 2017 foram realizadas saídas a campo, reuniões e oficinas (Figuras 10A a 10D) que culminaram em um projeto de jardim naturalista com 33 espécies nativas do Cerrado. Com verba levantada por financiamento coletivo, doações e venda de adesivos, o jardim foi implantado em 07/12/2017, em um esforço que envolveu mais de 40 voluntários (Figuras 10E a 10F).
Foram plantadas cerca de 700 mudas e introduzidos cerca de $7 \mathrm{~kg}$ de sementes (Tabela 2). As mudas foram produzidas pelo viveiro experimental em Alto Paraíso-GO e a maior parte das sementes foi coletada pela Associação Cerrado de Pé (GO) e doada pela Rede de Sementes do Cerrado (DF). Algumas espécies foram plantadas e semeadas (Figuras 10G a 10N), permitindo a posterior comparação do desenvolvimento das plantas em ambas as técnicas, acompanhando discussões propostas por Hitchmough (2004; 2017).

A área tem sido mantida por alunos e professores da UnB (inclusive no âmbito de disciplinas de graduação), voluntários e, mais recentemente, por um jardineiro contratado. $O$ Jardim também é assunto de pesquisas com temas relacionados à botânica, ecologia, entomologia, ensino de ciências e percepções ambientais de espaços verdes.

Realizaram o Jardim Louise Ribeiro: Ateliê Muda, Bambuco, prof. Camila Sant'Anna (UFG), Coordenação de Parques e Jardins da Prefeitura do Campus da UnB, Faculdade de Arquitetura e Urbanismo da UnB, Grupo Ipê Rosa, Instituto de Ciências Biológicas da UnB, Jardins de Cerrado.
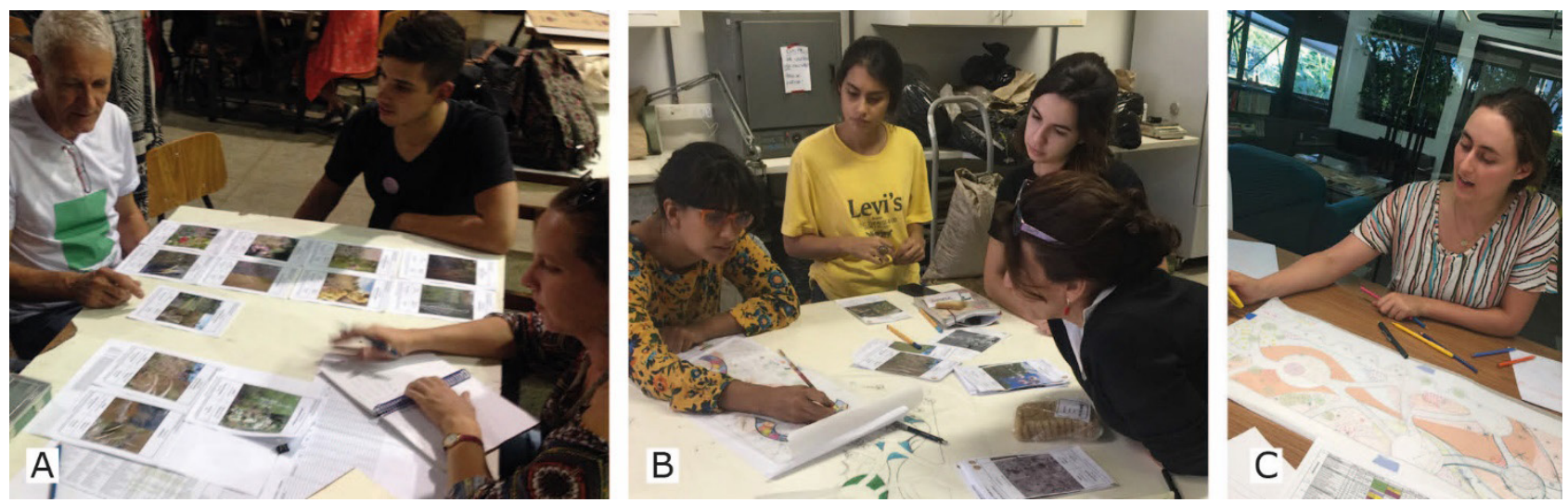

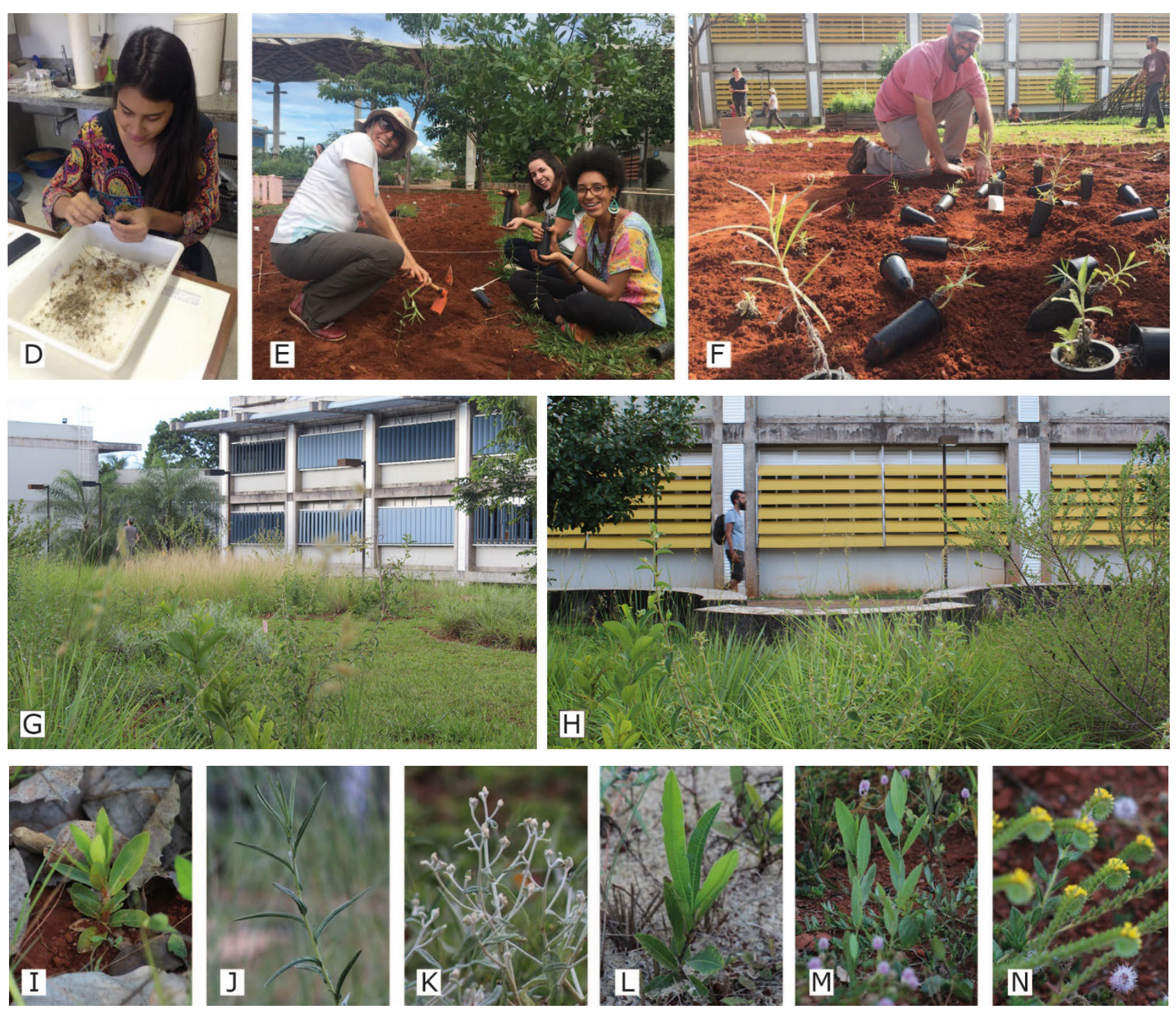

Figura 10 - A-C. Oficinas e reuniões de projeto em 2016 e 2017; D. Oficina de beneficiamento de sementes em 24/10/2017: E e F. Semeadura e plantio de mudas no jardim em 07/12/2017; G e H. Vistas gerais do jardim que domina os canteiros centrais em 17/02/2020; I-M. Espécies nativas introduzidas por mudas e sementes, 24/05/2018; N. Espécie de surgimento espontâneo mantida no jardim, 24/05/2018. Fotos: Mariana Siqueira, datas supramencionadas. 


\section{Parque da Asa Sul (dezembro, 2017)}

Contribuir com a criação e fortalecimento de cadeias produtivas de sementes, difundir conhecimentos acerca de técnicas eficazes e de baixo custo para reintrodução da flora nativa em ambientes de diversas escalas e promover o uso de plantas do Cerrado no paisagismo. Com esses objetivos, em 2017, a Rede de Sementes do Cerrado (RSC) lançou, em parceria com o projeto Jardins de Cerrado e com patrocínio do Instituto Caixa Seguradora, o projeto As cores do Cerrado em jardins urbanos.

A primeira ação do projeto foi feita em parceria com o Instituto Brasília Ambiental (Ibram), visando à criação do primeiro Jardim de Cerrado em um parque público no Distrito Federal. Por meio de uma oficina de dois dias (09 e 10/12/2017), apresentamos possibilidades projetuais para gestores ambientais, técnicos de órgãos da manutenção de áreas verdes públicas e produtores de espécies ornamentais, entre outros. No primeiro dia, foi elaborado coletiva- mente um projeto de jardim de Cerrado com 18 espécies de plantas nativas (Tabela 2), com ênfase em capins e subarbustos. No dia seguinte, foram feitas a demarcação do projeto e a semeadura direta ${ }^{2}$ (Figura 11A).

Ao longo de um ano, voluntários se reuniram periodicamente para fazer a manutenção do jardim. Ao fim do período, em 26/01/2019 a RSC e os Jardins de Cerrado organizaram nova oficina, dessa vez com patrocínio do Critical Ecosystem Partnership Fund, no contexto do projeto Mercado de Sementes e Restauração, provendo serviços ambientais e biodiversidade, para atualizar o projeto em função de novas espécies coletadas em 2018 e ressemear algumas áreas (Figura 11B). Somadas às 12 espécies que se estabeleceram a partir da semeadura inicial, foram introduzidas sementes de oito novas plantas.

Ao longo de todo o processo, participou o professor Júlio Barêa Pastore, da FAV/UnB.
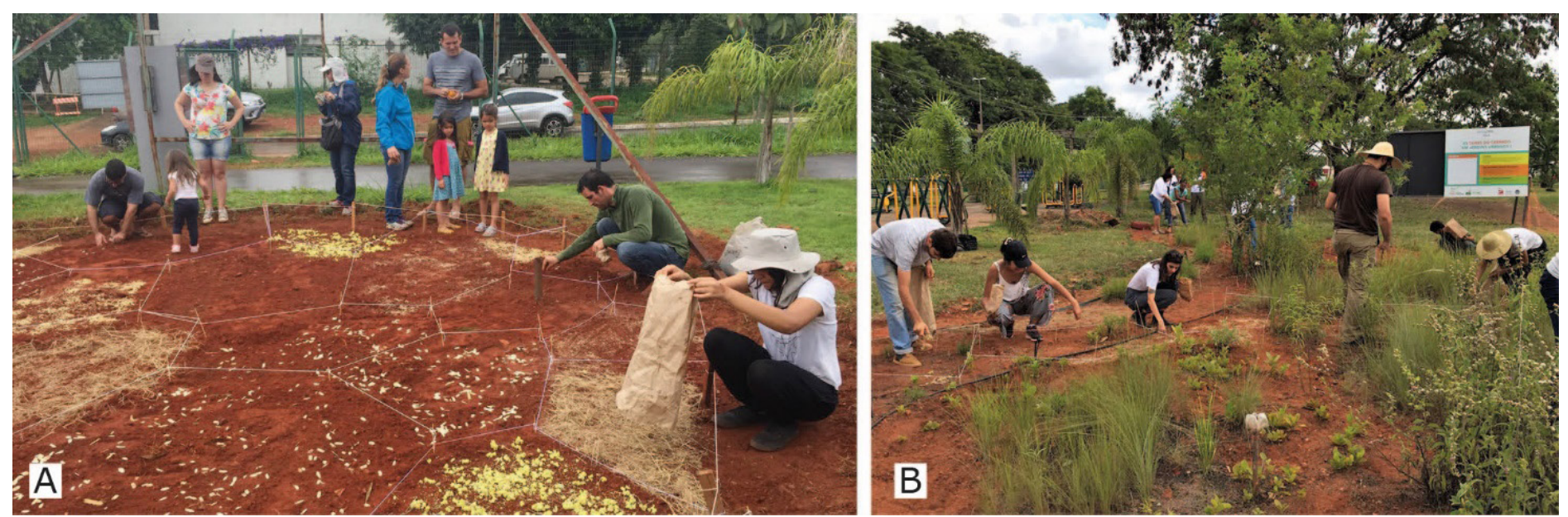

Figura 11 - A. Semeadura inicial do Jardim de Cerrado do Parque da Asa Sul; B. Oficina de ressemeadura do jardim em 26/01/2019. Fotos: Mariana Siqueira, 2017 e 2018.

2 Dessas atividades resultou o vídeo As cores do Cerrado em jardins urbanos, disponível em https://www.youtube. com/watch?v=050h8LFldwc\&t=24s 
Tabela 2 - Ervas e subarbustos nativos do Cerrado utilizados nos projetos apresentados neste artigo.

\begin{tabular}{|c|c|c|c|c|c|c|}
\hline Família botânica & Espécie & VE & JBB & $\mathrm{CC}$ & JLR & PAS \\
\hline Anacardiaceae & Anacardium humile A.St.-Hil. & $\mathrm{S}$ & S & S & MS & S \\
\hline Apiaceae & Eryngium juncifolium (Urb.) Mathias \& Constance & $S$ & & & MS & \\
\hline \multirow{16}{*}{ Asteraceae } & Achyrocline satureioides (Lam.) DC. & S & S & S & MS & $\mathrm{S}$ \\
\hline & Aldama bracteata (Gardner) E.E.Schill. \& Panero & $\mathrm{S}$ & & & MS & S \\
\hline & Aldama filifolia (Sch.Bip. ex Baker) E.E.Schill. \& Panero & $\mathrm{S}$ & & & $\mathrm{M}$ & 0 \\
\hline & Aldama robusta (Gardner) E.E.Schill. \& Panero & & & S & $\mathrm{S}$ & \\
\hline & Calea fruticosa (Gardner) Urbatsch, Zlotsky \& Pruski & $\mathrm{S}$ & & & & \\
\hline & Calea villosa Sch.Bip. ex Bake & S & & & & \\
\hline & Chresta exsucca DC. & $\mathrm{S}$ & & $S$ & $\mathrm{~S}$ & O \\
\hline & Chresta scapigera (Less.) Gardner & $\mathbf{S}$ & & & & \\
\hline & Chresta sphaerocephala DC. & $\mathbf{S}$ & $\mathbf{S}$ & & & \\
\hline & Dimerostemma brasilianum Cass. & $\mathbf{S}$ & & & & \\
\hline & Eremanthus uniflorus MacLeish \& H.Schumach. & $\mathbf{S}$ & $\mathbf{S}$ & & & 0 \\
\hline & Lepidaploa aurea (Mart. ex DC.) H.Rob. & S & $\mathrm{S}$ & $\mathbf{S}$ & MS & S \\
\hline & Lepidaploa rufogrisea (A.St.-Hil.) H.Rob. & $\mathbf{S}$ & & $\mathbf{S}$ & M & $\mathbf{S}$ \\
\hline & Lessingianthus fonsecae (H.Rob.) H.Rob. & S & & & & \\
\hline & Trichogonia prancei G.M.Barroso & $\mathbf{S}$ & & & & \\
\hline & Vernonanthura polyanthes (Sprengel) Vega \& Dematteis & $\mathbf{S}$ & $\mathbf{S}$ & $\mathbf{S}$ & $\mathrm{S}$ & \\
\hline \multirow{4}{*}{ Bignoniaceae } & Anemopaegma arvense (Vell.) Stellfeld ex de Souza & $\mathbf{S}$ & & & M & \\
\hline & Fridericia platyphylla (Cham.) L.G.Lohmann & $\mathrm{S}$ & & $\mathbf{S}$ & MS & $\mathbf{S}$ \\
\hline & Jacaranda ulei Bureau \& K.Schum. & $\mathrm{s}$ & & S & & \\
\hline & Zeyheria montana Mart. & S & & S & $\mathrm{S}$ & \\
\hline Bromeliaceae & Dyckia lunaris & $\mathrm{S}$ & & & $\mathrm{M}$ & \\
\hline Calophyllaceae & Kielmeyera rubriflora Cambess. & $\mathrm{s}$ & & & & \\
\hline \multirow{2}{*}{ Cyperaceae } & Rhynchospora consanguinea (Kunth) Boeckeler & $\mathrm{S}$ & & & & \\
\hline & Rhynchospora globosa (Kunth) Roem. \& Schult. & $\mathrm{S}$ & & & & 0 \\
\hline
\end{tabular}




\begin{tabular}{|c|c|c|c|c|c|c|}
\hline Eriocaulaceae & Paepalanthus chiquitensis Herzog & $\mathrm{S}$ & & & & \\
\hline \multirow{10}{*}{ Fabaceae } & Bauhinia dumosa Benth. & $\mathbf{S}$ & & & & 0 \\
\hline & Calliandra dysantha Benth. & $\mathbf{S}$ & & & & \\
\hline & Chamaecrista pachyclada (Harms) H.S.Irwin \& Barneby & S & & & & \\
\hline & Chamaecrista latistipula (Benth.) Afr. Fern \& E. Nunes & $\mathbf{S}$ & & & & \\
\hline & Eriosema glabrum Mart. ex Benth. & $\mathbf{S}$ & & & MS & \\
\hline & Harpalyce hilariana Benth. & S & & & M & \\
\hline & Mimosa speciosissima Taub. & S & & & S & $\mathbf{S}$ \\
\hline & Mimosa claussenii Benth. & $\mathrm{S}$ & & & M & \\
\hline & Senna alata (L.) Roxb. & & $\mathbf{S}$ & & & \\
\hline & Senna rugosa (G.Don) H.S.Irwin \& Barneby & $\mathbf{S}$ & & & M & \\
\hline Iridaceae & Trimezia juncifolia (Klatt) Benth. \& Hook. & $\mathrm{S}$ & & & & \\
\hline \multirow{2}{*}{ Lamiaceae } & Hypenia brachystachys (Pohl ex Benth.) Harley & $\mathrm{s}$ & & $\mathrm{S}$ & $\mathrm{S}$ & $\mathrm{S}$ \\
\hline & Hyptis dictyodea Pohl ex Benth. & $\mathrm{S}$ & & & & \\
\hline \multirow{14}{*}{ Poaceae } & Andropogon fastigiatus Sw. & $\mathrm{S}$ & S & & $\mathrm{S}$ & \\
\hline & Andropogon leucostachyus Kunth & & & & & $\mathrm{S}$ \\
\hline & Aristida flaccida Trin. \& Rupr. & & $\mathrm{S}$ & & & \\
\hline & Aristida riparia Trin. & $\mathrm{S}$ & S & $S$ & MS & $\mathrm{S}$ \\
\hline & Aristida gibbosa (Nees) Kunth & $\mathrm{S}$ & & & & 0 \\
\hline & Axonopus aureus P. Beauv. & $\mathrm{S}$ & & $\mathrm{S}$ & MS & \\
\hline & Axonopus pellitus (Nees ex Trin.) Hitchc. \& Chase & $\mathrm{S}$ & & S & MS & $\mathrm{S}$ \\
\hline & Ctenium cirrosum (Nees) Kunth & $\mathrm{S}$ & & & & \\
\hline & Gymnopogon foliosus (Willd.) Nees & $\mathrm{S}$ & & & & \\
\hline & Loudetiopsis chrysothrix (Nees) Conert & $\mathrm{S}$ & $\mathrm{S}$ & & $\mathrm{S}$ & \\
\hline & Paspalum stellatum Humb. \& Bonpl. ex Flüggé & $\mathrm{S}$ & & & & \\
\hline & Ocellochloa chapadensis (Swallen) Zuloaga \& Morrone & $\mathrm{S}$ & & & & O \\
\hline & Schizachyrium sanguineum (Retz.) Alston & $\mathrm{S}$ & $\mathrm{S}$ & & MS & 0 \\
\hline & Trachypogon spicatus (L.f.) Kuntze & $\mathrm{S}$ & & S & MS & $\mathrm{S}$ \\
\hline
\end{tabular}




\begin{tabular}{l|l|c}
\hline Rubiaceae & Borreria capitata & $\mathrm{S}$ \\
\hline Solanaceae & Solanum lycocarpum A.St.-Hil. & $\mathrm{S}$ \\
\hline Verbenaceae & Stachytarpheta villosa (Pohl) Cham. & $\mathrm{S}$ \\
\hline Vochysiaceae & Vochysia pumila Pohl & $\mathrm{S}$ \\
\hline Xyridaceae & Xyris sp. & $\mathrm{S}$ \\
\hline
\end{tabular}

\section{Legendas:}

VE: Viveiro Experimental

JBB: Experimento no Jardim Botânico de Brasília

CC: Casa no Cerrado

JLR: Jardim Louise Ribeiro

PAS: Parque da Asa Sul

\section{Conclusão}

As experiências iniciais do projeto Jardins de Cerrado demonstram que a introdução de plantas nativas do Cerrado ao paisagismo é um caminho viável e promissor. Esse é um processo longo e complexo que, para resultar em uma efetiva mudança na cultura paisagística, deve contar com múltiplos agentes (paisagistas, viveiristas, clientes, pesquisadores e estudantes, em esferas públicas e privadas), operando, preferivelmente, em redes interdisciplinares.

Superada a crença errônea de que as plantas do estrato herbáceo -arbustivo do Cerrado não se prestam ao cultivo e à introdução em paisagens construídas, abrem-se inúmeras possibilidades - e necessidades - de pesquisas. Solos (entendidos em seus aspectos físicos, químicos e biológicos), cultivo de plantas e sua inserção em jardins, processos de projeto e implantação, irrigação (e sua potencial redução ou mesmo eliminação), manutenção, relações entre flora, fauna e microrganismos e percepção do público são apenas
S: Espécie introduzida com êxito por sementes

M: Espécie introduzida com êxito por mudas (produzidas por sua vez a partir de sementes)

O: Espécies introduzidas no período de submissão deste artigo, com dados a coletar.

Fonte: autores.

algumas das facetas da grande empreitada que é a introdução da flora nativa ao paisagismo.

As atividades apresentadas neste artigo propõem conceitos, processos e metodologias que podem servir como base para futuras pesquisas. As satisfatórias experiências que tivemos nesses quatro anos iniciais nada mais são que os primeiros passos de uma longa caminhada.

\section{Referências Bibliográficas}

AGUIAR, LM de S.; MACHADO, Ricardo Bomfim; MARINHO-FILHO, Jader. A diversidade biológica do Cerrado. Ecologia e caracterização do Cerrado, p. 19-42, 2004.

BFG - The Brazil Flora Group. Growing knowledge: an overview of Seed Plant diversity in Brazil. Rodriguésia, v. 66, n. 4, p. 1-29, 2015. DOI: http://dx.doi. org/10.1590/2175-7860201566411 
BOKOS, Helena. Jardins de Cerrado: Ideias para a criação de uma identidade paisagística utilizando a flora nativa. 2017. 47f. Ensaio teórico (Graduação em Arquitetura e Urbanismo) - Faculdade de Arquitetura e Urbanismo da Universidade de Brasília, Brasília, 2017

BOND, William J. Open ecosystems: ecology and evolution beyond the forest edge. Oxford University Press, 2019.

BOND, William J.; KEELEY, Jon E. Fire as a global 'herbivore': the ecology and evolution of flammable ecosystems. Trends in ecology \& evolution, v. 20, n. 7, p. 387-394, 2005. DOI: 10.1016/j.tree.2005.04.025

BUSTAMANTE, Mercedes. Desmatar o Cerrado é "fechar a torneira da água", diz especialista. Valor Econômico, 21 jul. 2015, Especial, A12. Entrevista concedida a Daniela Chiaretti. Disponível em < https://www valor.com br/brasil/4142706/desmatar-o-cerrado -e-fechar-torneira-da-agua-diz-especialista> Acesso em 22 maio. 2019.

CABALLERO, Daniel. Guia de campo dos Campos de Piratininga ou O que sobrou do cerrado paulistano ou Como fazer seu próprio Cerrado Infinito. São Paulo: La Luz del Fuego, 2016

CAMILO, Rosana de Andrade et al. Visitantes florais em Lepidaploa aurea: arbusto para restauração de Cerrado. In: IX Seminário de Pesquisa e IX Encontro de Iniciação Científica do Instituto Chico Mendes de Conservação da Biodiversidade, 9., 2018, Brasília. Anais. Brasília: Instituto Chico Mendes de Conservação da Biodiversidade - ICMBio, 2018. p. 133

CHAVES, Rafael B. et al. On the need of legal frameworks for assessing restoration projects success: new perspectives from São Paulo state (Brazil). Restoration Ecology v. 23, n. 6 , p. 754-759, 2015. DOI: https://doi.org/10.1111/rec.12267

COELHO, Augusto. Manejo de plantas nativas do Cerrado para paisagismo. 2019

Trabalho no Programa Institucional de Bolsas de Iniciação Científica, PIBIC (Graduação em Ciências Biológicas) - Universidade de Brasília, Braśília, 2019.

DOURADO, Guilherme Mazza. Modernidade verde: jardins de Burle Marx. São Paulo: Editora Senac São Paulo, 2009.

DUNNETT, Nigel; HITCHMOUGH, James. The dynamic landscape. Londres e Nova Iorque: Spon Press, 2004

DURIGAN, Giselda et al. Plantas pequenas do cerrado: biodiversidade negligenciada. 1 ed. São Paulo: Secretaria do Meio Ambiente, 2018.

GDF - Governo do Distrito Federal. Concurso para o Masterplan da Orla Livre do Lago Paranoá. Disponível em <http://concurso.orlalivre.df.gov.br/> Acesso em 04 de abril de 2019.

GRANZOTTO, Marina. Análise do crescimento inicial de espécies herbáceas e subarbustivas do Cerrado para fins paisagísticos. 2018. 49f. Trabalho final de curso (Graduação em Engenharia Florestal) - Departamento de Engenharia Florestal da Universidade de Brasília, Brasília, 2018.

HITCHMOUGH, James. Naturalistic herbaceous vegetation for urban landscapes. In: The dynamic landscape. Londres e Nova lorque: Spon Press, 2004. p. 172-254.

HITCHMOUGH, James. Sowing beauty: designing flowering meadows from seed. 1. ed. Portland: Timber Press, 2017.

IPAM. Cerrado é desmatado cinco vezes mais rápido que a Amazônia. Instituto de pesquisa ambiental da Amazônia (IPAM), 2017. Disponível em <http://ipam.org.br/ cerrado-e-desmatado-cinco-vezes-mais-rapido-que-amazonia/> Acesso em 22 de maio de 2019
KLINK, Carlos A.; MACHADO, Ricardo B. Conservation of the Brazilian cerrado. Conservation biology, v. 19, n. 3, p. 707-713, 2005.

KUBITSCHEK, Juscelino. Por que construí Brasília. Senado Federal, Conselho Editorial 2006.

MELLO, Soraia Silva de; PASTORE, Júlio Barêa. Ornamental flora of the Cerrado in landscape architecture: a portrait of its practical application. Ornamental Horticulture, v. 27 , n. 1 , p. 78-87, 2021

MENDONÇA, RC de et al. Flora vascular do bioma Cerrado: checklist com 12.356 espécies. Cerrado: ecologia e flora, v. 2, p. 422-442, 2008.

MYERS, Norman et al. Biodiversity hotspots for conservation priorities. Nature, v. 403 n. 6772 , p. 853,2000

OVERBECK, Gerhard E. et al. Conservation in Brazil needs to include non-forest ecosystems. Diversity and distributions, v. 21, n. 12, p. 1455-1460, 2015. DOI: https://doi. org/10.1111/ddi.12380

OUDOLF, Piet; KINGSBURY, Noel. Planting: a new perspective. 1. ed. Timber Press, 2013 PASTORE, Júlio Barêa. O cerrado enquanto paisagem: a dinâmica da apropriação paisagística do território. 2014. 266f. Tese (Doutorado em Arquitetura e Urbanismo) Faculdade de Arquitetura e Urbanismo da Universidade de São Paulo, São Paulo, 2014 PELLIZZARO, Keiko Fueta et al. "Cerrado" restoration by direct seeding: field establishment and initial growth of 75 trees, shrubs and grass species. Brazilian Journal of Botany, v. 40, n. 3, p. 681-693, 2017. DOI: 10.1007/s40415-017-0371-6

PIVELLO, Vânia Regina; SHIDA, Cláudia Nagako; MEIRELLES, Sérgio Tadeu. Alien grasses in Brazilian savannas: a threat to the biodiversity. Biodiversity \& Conservation, v. $8, n$ 9, p. 1281-1294, 1999

RIBEIRO, José Felipe; WALTER, Bruno Machado Teles. As principais fitofisionomias do bioma Cerrado. Cerrado: ecologia e flora, v. 1, p. 151-212, 2008.

SAMPAIO, Alexandre Bonesso et al. Guia de restauração do Cerrado: volume 1: semeadura direta. Embrapa Cerrados-Livro técnico (INFOTECA-E), 2015.

SIMON, Marcelo F. et al. Recent assembly of the Cerrado, a neotropical plant diversity hotspot, by in situ evolution of adaptations to fire. Proceedings of the National Academy of Sciences, v. 106, n. 48, p. 20359-20364, 2009. DOI: www.pnas.org/cgi/ doi/10.1073/pnas.0903410106

SIQUEIRA, Mariana. Jardins de Cerrado: potencial paisagístico da savana brasileira. Revista VARAU, n. 4, p. 32-46, 2016. Disponível em < https://portalrevistas.ucb br/index. $\mathrm{php} /$ CAU/article/view/7065/4384 > Acesso em 25 maio. 2018.

SIQUEIRA, Mariana et al. More than trees. Landscape Architecture Frontiers, v. 5, n. 5, p. 144-153, 2017. DOI: https://doi.org/10.15302/J-LAF-20170514

SOUSA, Artur de Paula; VIEIRA, Daniel Luis Mascia. Protocolo de monitoramento da recomposição da vegetação nativa no Distrito Federal. WWF, 2017.

TABACOW, José. (Org.). Roberto Burle Marx: arte e paisagem: conferências escolhidas. 2.ed. São Paulo: Studio Nobel, 2004.

VELDMAN, Joseph W. et al. Tyranny of trees in grassy biomes. Science, v. 347, n. 6221 p. 484-485, 2015a. DOI: 10.1126/science.347.6221.484-c

VELDMAN, Joseph $\mathrm{W}$. et al. Where tree planting and forest expansion are bad for biodiversity and ecosystem services. BioScience, v. 65, n. 10, p. 1011-1018, 2015b. WHITE, Robin P. et al. Grassland ecosystems. Washington DC: World Resources Institute, 2000 . 


\section{Agradecimentos}

Agradecemos a todas as pessoas e instituições que contribuíram com visão, trabalho e entusiasmo para as ações e formulações iniciais do projeto Jardins de Cerrado.

Mariana de Melo Siqueira

Escritório Jardins de Cerrado

SBN Quadra 02 Bloco F Sala 509. CEP 70.041-906. Brasília-DF, Brasil.

https://orcid.org/0000-0002-0709-7015

contato@marianasiqueira.com

\section{Alexandre Sampaio}

Centro Nacional de Avaliação da Biodiversidade e de Pesquisa e

Conservação do Cerrado

Instituto Chico Mendes de Conservação da Biodiversidade - ICMBio

EQSW 103/104, Bloco "C", Complexo Administrativo - Setor Sudoeste.

CEP 70.670-350. Brasilia-DF, Brasil

https://orcid.org/0000-0002-3010-4607

alexandre.sampaio@icmbio.gov.br

\section{Amalia Robredo}

Universidad de la República, Uruguay

Campus Universitario Regional Este, Av. Cachimba del Rey, 20100.

Punta del Este, Departamento de Maldonado, Uruguay

http://orcid.org/0000-0003-3846-6036

amaliarobredo@gmail.com

Claudomiro de Almeida Cortes

Associação de Coletores de Sementes Cerrado de Pé

Rua Abílio Domingues, Quadra 31, Lote Parte da APM. CEP 73.770-000.

Alto Paraíso de Goiás-GO. Brasil.

https://orcid.org/0000-0002-7987-2746

clau.almeidacortes@gmail.com

João Bernardo de A. Bringel Jr

Universidade de Brasília, Instituto de Ciências Biológicas,

Departamento de Botânica.

Campus Universitário Darcy Ribeiro, CEP 70.910-900. Brasília-DF, Brasil. https://orcid.org/0000-0001-8423-2930

jbbringel@gmail.com
Keiko Fueta Pellizzaro

Instituto Chico Mendes de Conservação da Biodiversidade - ICMBio

Parque Nacional de Brasília. DF 003, Via Epia, Km 8,5. CEP 70.635-800.

Brasília-DF, Brasil.

https://orcid.org/0000-0001-6729-8276

keiko.pellizzaro@icmbio.gov.br

Isabel Belloni Schmidt

Universidade de Brasília, Instituto de Ciências Biológicas,

Departamento de Ecologia

Campus Universitário Darcy Ribeiro. CEP 70.910-900. Brasília-DF, Brasil.

https://orcid.org/0000-0001-9420-6509

isabels@unb.br

\section{Nota do Editor}

Recebido em: 23/05/2019

Aprovado em: 15/05/2021

Revisado: 